\title{
新工科视域下青岛大学应用化学专业创新人才培养实践
}

吕洲 ${ }^{*}$, 朱倩倩, 李群, 王宗花, 毕赛

青岛大学化学化工学院, 山东青岛 266071

摘要：面对新技术、新业态、新产业快速发展的需要和国家重大发展战略需求, 青岛大学应用化学专业按照复合型 人才培养理念, 以实施 “海洋强国战略” 为背景, 按照新工科理念对应用化学专业进行改造升级, 打造 “海洋化工 与药物” 特色方向。本文结合专业培养方案修订, 增加海洋资源化学特色课程和课程模块, 改革课程教学内容, 开 展特色人才培养, 对以新工科理念改造升级传统专业具有一定的指导意义。

关键词: 新工科; 应用化学; 海洋资源化学; 综合教学改革

中图分类号: G64; O6

\section{Cultivation Innovative Talents of Applied Chemistry Specialty in Qingdao University under the Guidance of the Emerging Engineering Education}

\author{
Zhou Lü *, Qianqian Zhu, Qun Li, Zonghua Wang, Sai Bi \\ College of Chemistry and Chemical Engineering, Qingdao University, Qingdao 266071, Shandong Province, P. R. China.
}

\begin{abstract}
Owing to the rapid development of new technologies, new forms of business, new industries and the major national development strategies of "Maritime power strategy", the applied chemistry specialty of Qingdao University is reformed and upgraded according to emerging engineering education (3E) project and featured with "marine chemical industry and medicine". In this paper, combined with the revision of the professional training program, the specialty of applied chemistry has increased the characteristic courses and course module of marine resources chemistry. Meanwhile, the course content is reformed, and the characteristic talent training is emphasized, which is of guiding significance for reforming and upgrading the traditional majors with $3 \mathrm{E}$ concepts.
\end{abstract}

Key Words: Emerging engineering education; Applied chemistry; Marine resource chemistry;

Comprehensive teaching reform

近年来, 为面向新工程体系, 培养能够引领未来产业发展的领导型工科人才, 世界一流大学纷 纷对工程教育进行了系统的反思和新一轮的教育改革。在此背景下, 我国积极推进 “新工科” 建设, 先后形成了 “复旦共识” “天大行动” 和 “北京指南”, 并发布了《关于开展新工科研究与实践的通 知》《关于推进新工科研究与实践项目的通知》, 全力探索形成满足新技术革命对人才需求的中国模 式 ${ }^{[1-7]}$ 。针对新工科建设内容, 教育部发文明确其所涉及的 “五个新” : 树立工程教育 “新理念” 创新型、综合化、全周期; 构建学科专业 “新结构” ——新兴工科和传统工科相结合; 探索实施工 程教育人才培养的 “新模式” ; 打造工程教育 “新质量” ——具有国际竞争力; 建立完善中国特色 
工程教育的 “新体系”。这 “五个新” 包含了新工科的基本内涵 ${ }^{[8]}$ 。在地方和行业高校中, 专业与区 域经济发展结合紧密, 在行业或区域产业形态发生变化时必然需要对自身人才培养的体系和内容进 行调整和改造, 以适应产业的变化。因此, 地方和行业高校面临着以 “新工科” 的理念和思路对传 统专业进行改造和建设的迫切需要 ${ }^{[9]}$ 。

青岛作为滨海城市, 依托得天独厚的地理位置优势和海洋资源的禀赋优势。2017 年, 山东省政 府根据《山东半岛蓝色经济区发展规划》和《山东省 “十三五” 人才发展规划》确定的发展重点和 主要任务, 重点引进和资助涉海人才。涉海科技人才需求旺盛, 创立涉海、涉化学新工科有其必要 性和合理性。海洋经济的快速发展离不开科技和人才的支持, 而高校作为专业人才培养的摇篮, 必 须调整培养方向, 服务于国家建设和社会需求。应用化学专业作为青岛大学传统优势专业, 旨在为 国家建设培养能在与化学相关的海洋资源化学、现代工业分析、能源及生命分析等领域从事应用研 究、技术研发、产品设计与营销、生产管理的高级技术人才和基础研究的创新型拔尖人才 ${ }^{[10]}$ 。近年 来, 专业以实施 “海洋强国战略” 为背景, 按照 “前沿技术引领性” “知识体系多样性” “人才培养 创新性” 等新工科重点强调的内涵, 加强面向新技术、新产业、新业态、新模式的专业建设, 实施 专业改造升级, 着重打造 “海洋化工与药物” 特色方向, 着力培养海洋资源化学领域多元化、创新 型卓越人才, 强化海洋科技研发能力, 助力青岛海洋经济发展走向深蓝。

\section{1 新工科背景下应用化学专业的改造理念}

\section{1 我校应用化学专业的历史沿革}

应用化学专业建于 1987 年, 学科特色明显, 目前有 “海洋化工与药物” “现代工业分析与检测 技术” “化学生物学” 和 “能源及纳米材料” 四个方向。1998 年获批应用化学硕士学位点, 2017 年 获批化学一级学科硕士点, 共享材料科学与工程博士学位点。应用化学属于化学一级学科, 2016 年 进入 ESI (基本科学指标数据库)学科排名全球前 $1 \%, 2019$ 软科发布的 “中国最好学科排名” 位于化 学学科全国第 76 位, 进入前 $34 \%, 2020$ 年 5 月进入 ESI 学科排名全球前 5\%, 是山东省立项重点 建设的一流学科, 2019 年入选首批国家一流本科专业建设点。

\section{2 应用化学专业新工科改造的主要理念}

以 “新工科” 为契机, 我校应用化学专业面向未来新技术、新产业、新经济的发展, 通过理工 交叉融合推进专业转型升级, 强化学生用科学方法解决重大工程问题的能力, 建立应用型创新人才 培养模式, 致力于培养既具有扎实基础理论、工程经验, 又有人文底蕴、家国情怀的新世纪复合型 高素质人才。

推进专业新工科改造, 一是强化应用化学专业的理科基础。基础学科不仅构成了新兴工科最初 的知识体系, 而且是技术创新的源泉。新工科就其本质而言具有内在的跨学科性和创新性, 需要汲 取不同学科知识体系的 “养分” , 实现交叉融合进而激发创新。二是继续推动应用理科向工科的延 伸, 促进科研新成果转化为新技术、新业态。新工科最终是面向产业发展的, 只有培养新工科化学 类专业人才, 才能满足和引领新兴产业进一步发展。

\section{3 应用化学专业新工科改造面临的问题}

“海洋化工与药物”作为我校应用化学专业特色方向, 在新工科改造过程中面临以下问题:

1) 部分课程建设相对滞后于产业发展, 教学内容缺乏海洋资源化学领域的基本知识和新技术, 教 学和实践出现脱节。2) 对 “海洋化工与药物” 专业方向进行新工科改造, 需进一步优化专业人才 培养模式, 使人才培养模式与产业需求相对应, 培养符合国家重大需求和学科发展亟需的人才。 3) “海洋化工与药物” 专业方向缺乏具有丰富工程实践背景的教师。受学校评价机制等多方面因 素的影响, 高校教师大部分以科学研究为主, 工程教育背景相对薄弱。4) 缺少实验平台, 没有形 成校企深度融合机制, 学生缺乏实验、实践的土壤。5) 缺乏与信息化技术、人工智能以及自动化 控制系统等先进技术手段的结合与应用。 
针对我校应用化学专业的不足, 在近年来的新工科改造中, 我们通过优化本专业人才培养方案, 实施创新创业人才培养模式, 改革课程体系和教学内容, 强化教师队伍建设等途径保障学生的知识、 能力和素质目标的实现，提高人才培养质量。

\section{2 新工科改造的主要举措和成效}

\section{1 优化专业人才培养方案}

应用化学专业人才培养方案的修订工作始终贯彻 “以学生发展为中心” 的理念, 保障人才培养 多层次目标。结合 “海洋化工与药物” 特色方向进行模块与课程设置, 强化学生的海洋意识, 着力 提高学生开展海洋资源开发的能力, 努力构建以学生发展为中心的教育教学服务体系。

\subsection{1 “海洋化工与药物”方向人才需求现状}

新兴海洋产业是 “十四五” 期间培育和发展未来产业的重点领域。我国海洋人才培养和队伍建 设虽取得长足进展, 但与新时代海洋强国建设需求之间仍存在差距。近年来各海洋相关专业的博硕 士研究生、本专科生的数量都在稳步增加。《中国海洋统计年鉴(2017)》显示, 2016 年全国开设海洋 专业的高等院校达 537 个, 全国拥有海洋科研机构 160 个。目前仍存在海洋领域专业设置尚不够全 面、复合型海洋人才严重贵乏、海洋人才队伍技术结构失调、专业人员比例偏低、海洋科研队伍分 散等问题。海洋特色产业科技成果转化效率不高, 海洋科技人才的创新能力也有待进一步提升。“海 洋化工与药物” 方向作为应用化学专业的特色方向, 具有典型的学科交叉特点, 未来的发展具有很 高的可期性。

\subsection{2 “海洋化工与药物” 方向培养目标和培养要求}

采用化学大类招生培养模式, 以通识教育和专业教育为基本阶段, 有利于打破专业界限, 培养 学生基础素质, 丰富学生知识范围, 学生在入学第一年集中学习通识类课程和学科大类基础课程, 大三进入不同专业方向学习。学生培养实行学分制, 学生在四年内共需完成 160 个学分, 其中必修 课占 $65 \%$ 左右, 各类选修课占 $35 \%$ 左右, 给学生提供了较多的自主权, 充分发挥各类学生的才能和 特长。

培养目标：培养能在海洋化工与制药领域中从事应用研究、技术开发、产品设计、市场营销及 科技和生产管理的复合型技术人才和创新型拔尖人才。突出以 “海洋化工与药物” 为中心的专业特 色, 体现专业设置的前瞻性、先进性, 体现专业方向间的区分度及关联性。体现理工结合和扎实的 基础理论、基础知识和基本技能的专业 “三基” 。

培养要求:

(1) 具有高度的社会责任感、良好的科学文化素养和较强的创新意识;

(2) 系统掌握海洋化学基础知识、理论和技能, 了解海洋化学的知识体系、学科前沿、发展趋势 和应用前景;

(3) 接受较系统的科学思维和科学研究的基本训练, 初步具备综合运用化学及数学、物理学等 学科的基本内容进行研究和开发的能力;

（4）掌握一定的信息技术，具有获取、加工和应用信息的能力;

(5) 能够发现、提出、分析和解决问题, 具有从事化学研究和其他实际工作的能力;

（6）具有较强的学习、交流、协调能力和团队合作精神，适应学科和社会的发展;

(7) 具有一定的国际视野和跨文化背景下的交流、竞争与合作的能力。

\section{2 课程体系构建与教学内容改革}

(1) 2017 版专业培养方案注重理论和应用的专业方向课程模块。该专业方向的课程包含理论类 课程、应用类课程、讲座类课程以及专业实验。其中专业基础理论课程与其他专业方向相同, 包括 无机化学、分析化学、有机化学、物理化学等, 特色课程模块及课程见表 1 。 
表 1 海洋化工与药物专业方向的特色课程

\begin{tabular}{cl}
\hline 课程模块 & \multicolumn{1}{c}{ 主要课程 } \\
\hline 应用类课程 & 天然药物化学、仪器分析、绿色化学与技术、海洋化工产品概论、生物化学、海藻化工产品提取与和合成、 \\
& 药物化学研究与新药开发概论、应用化学专业英语、化学文献检索、化工技术经济、市场营销学等 \\
讲座类课程 & 高新技术讲座、夏季学期高端学术报告 \\
专业实验 & 海洋化工与药物实验 (I、II、III) \\
\hline
\end{tabular}

为落实 “海洋化工与药物” 的专业特色培养要求, 增加了海洋化工产品概论、海藻化工产品提 取和合成等专业方向课程; 为提高学生的实践动手能力, 增设了海洋化工与药物专业实验。这些课 程模块的设置, 在有效夯实 “海洋化工与药物” 方向学生的化学基础知识的同时, 提高了海洋意识, 为开展海洋资源开发与研究奠定了基础。

(2) 调整课程内容。修订教学大纲, 以课程在人才培养方案中的作用来设计教学目的、教学内 容, 保证教学环节的整体优化。借鉴国内外 “海洋化工与药物” 领域最新研究成果, 将海洋产业发 展的新知识、新技术、新成果纳入课程内容; 推进学科内容的交叉融合, 将课程内容与实际产业建 设需求结合, 拓宽海洋、环境、经济、法律法规等相关领域知识, 培养学生解决实际工程复杂问题 的能力。

（3）实验实践相关课程设置。专业实验设置海洋化工与药物实验; 大学生创新创业训练计划的 项目主要来源于学业导师科研课题; 通过实验实践相关课程, 有效提高了学生的动手实践能力。

(4) 深度挖掘教育教学资源, 发挥网络教育教学优势。树立 “以学生为中心” 的教育教学理念, 积极进行教学方法改革。自 2020 年春季学期起, 一批虚拟仿真实验教学项目投入到实际教学环节。 借助优质的线上课程学习平台如中国大学 MOOC 进行课程内容拓展。利用产学研合作的优质资源, 将最新的海洋产业前沿发展、案例纳入课程内容当中, 逐步形成具有系统性的教学内容。推进校级 和省级精品课程、双语示范课程等建设, 打造 “金课”, 培养学生解决复杂问题和综合问题的能力。

(5) 改进课程实施。借助互联网平台, 发展成新工科背景下 “互联网+”多种技术结合的混合式 教学模式。邀请海洋领域的工程师、专家等校外人士共同参与课程实施, 讲授更加具体的工程实际 问题。激励学生发挥主观能动性, 主动发现问题、分析问题、解决问题, 从研究性学习中促进学生 深度学习, 培养学生解决实际工程问题能力。

\section{3 创新创业人才培养模式}

实行学业导师制, 帮助学生做好学业规划。将培养目标、教育理念、课程体系、实践条件、课 外学习资源等融为一体, 贯穿于整个培养过程中, 提高人才培养质量。强化创新创业教育, 提升学 生实践能力: 一是将创新创业教育融入到课堂教学, 将国内外前沿的新理论、新技术融入课堂, 提 高学生的知识广度和深度; 二是不断探索实验教学的新手段, 培养科学研究和生产实践的能力; 三 是以课题研究带动实践教学, 将研究思维注入实践教学。大学生创新创业参与率 $95 \%$ 以上。

\section{4 “海洋化工与药物”方向专业实验平台建设}

实践教学在 “海洋化工与药物” 方向的新工科改造中占据重要地位, 它在培养学生观察能力、 分析及解决问题能力等方面具有不可替代的作用, 是培养学生创新能力和探索精神的有效途径之一。 目前本专业拥有青岛市海洋澳素资源综合利用工程技术研究中心、青岛大学应用化学研究所、青岛 大学海洋资源综合利用研究中心等科研平台, 同时, 学校还有青岛大学化学化工学院实验中心, 正 在不断推进虚拟仿真实验平台建设。此外, 设立 “海洋化工与药物” 专业方向开放实验室, 强化学 生课余时间的实践能力培养, 由学业导师对学生进行专业实验培训, 提高学生的自主动手能力, 让 学生掌握基本专业知识的同时还具备解决实际科学问题的能力。 


\section{5 强化教师队伍建设}

鼓励本专业教师进行国外访学，邀请企业工程师、校外专家形成了一批 “双师结构” 指导教师 队伍, 积极结合国内外优秀专家兼职授课的模式, 打造具有国际前沿视野的高水平本科人才培养队 伍, 提高专业人才培养质量。目前, 专业已形成了包括中科院院士、国家优青、泰山学者等在内的 一支高水平教师队伍, 拥有博士学位的比例提升至 $90 \%$, 近三年教师出国进修、交流超过 30 人次, 大大增强了教师队伍的国际化、前沿化, 有力保障了专业教学和人才培养。

\section{6 加强毕业生培养质量的跟踪调查和外部评价}

建立专业负责人牵头的 “三位一体” 毕业生质量评价体系, 包括应届毕业生去向登记制度, 及 时了解学生的深造和就业情况; 十年跟踪计划, 对毕业生中长期职业发展情况、培养质量的认同度 进行跟踪调查; 毕业生跟踪反馈与质量评价制度, 对毕业生及所在单位的持续跟踪回访, 了解毕业 生、用人单位对专业建设的建议, 持续改进人才培养模式。

通过过去多年的改革和建设, 毕业生对本专业教学满意度不断提升, “2018 年度社会需求与人 才培养质量综合报告” 显示, 毕业生就业满意度达到 $100 \%$ 。在创新型人才培养方面, 继续深造的学 生中, 出国及进入 “985” “双一流” 高校的学生比例超过 90\%, 大批毕业生取得博士学位后进入中 科院系统、知名高校从事科学研究, 涌现出多名国家级、省部级科研人才, 包括国家杰青、优青等 3 名。在应用型人才方面, 本专业理工结合培养模式为海洋药物、绿色化工等行业输送了一大批杰 出技术人才, 用人单位对毕业生的政治思想、工作态度、工作能力等方面给予了充分肯定。另外, 本专业一直坚持创业及实践教育模式, 培养了一大批杰出的创业人才, 涌现出杰正投资集团董事长、 伊森新材料股份有限公司董事长等多名化学相关行业企业家。

\section{3 结语}

在新工科背景下, 青岛大学大学应用化学专业人才培养任重道远, 目前依然存在海洋特色专业 课程偏少, 涉海内容不够精准, 实习基地、专业实践能力培养薄弱等问题。未来将继续推进专业建 设和教学改革, 面向国家经济社会快速发展的重大战略需求, 按照卓越工程师教育培养计划 2.0 和 基础学科拔尖学生培养计划 2.0 的总体思路和目标, 努力建成具有国际影响力的特色一流专业。

\section{参 考 文 献}

[1] 张树永, 朱亚先, 霍冀川, 宋丽娟, 徐华龙, 郑兰荪. 大学化学, 2020, 35 (10), 6.

[2] 林凌. 智库时代, 2019, 34, 194.

[3] 刘娅莉, 张小华, 周海晖, 何德良, 陈金华, 邓剑如, 李永军. 大学化学, 2018, 33 (9), 38.

[4] 张树永, 朱亚先. 中国大学教学, 2018, No. 3, 25.

[5] 张树永, 朱亚先. 中国大学教学, 2018, No. 7, 55.

[6] 高文秀, 王集思, 张浩, 连丽丽, 王希越, 娄大伟. 山东化工, 2019, 48 (22), 231.

[7] 张树鹏, 钟秦, 葛玲玲, 郝艳霞, 董伟. 大学化学, 2019, 34 (11), 103.

[8] 黄英, 李保国, 雷菁, 李为. 大学教育, 2020, No. 5, 20.

[9] 丁玉强, 朱亚先, 宋丽娟, 刘卫, 刘小珍, 霍冀川, 薛怀国, 郭荣, 廖青, 倪哲明, 等. 大学化学, 2020, $35(10), 33$.

[10] 李群, 吕洲. 中国大学教学, 2015, No. 10, 43. 